\title{
As competências na formação do engenheiro amazônida: perspectivas e desafios
}

\section{The skills in the training of the amazonian engineer: perspectives and challenges}

\author{
PASSOS DE OLIVEIRA, Antonio C. S. do N. ${ }^{1}$
}

\begin{abstract}
Resumo
O trabalho analisou a percepção do conceito de competência que os docentes, de um curso de referência na Amazônia Oriental, dispunham, comparando as percepções desses docentes com a ideia de que competência é formada por conhecimento, habilidades e atitudes. Esse estudo de carácter qualitativo pretendeu investigar essa percepção dos docentes pois, eles definirão o perfil de egresso e desenho curricular de um dos mais importes cursos de Engenharia Civil da região, segundo dados de órgãos do governo brasileiro. Foi utilizado um questionário semiaberto, o qual percebeu um fraco domínio sobre o conceito de competência, muitas das vezes, visualizando-o como sinônimo de habilidade, como também, $80 \%$ deles não percebeu a ausência das atitudes, na definição de competência.
\end{abstract}

Palavras-chave: competência, aprendizagem, perceção, atitude

\begin{abstract}
The present survey analyzed the interpretation of the concept of competence that teachers from a reference course in the Eastern Amazon had and compared their perceptions with the idea that 'competence' comprises knowledge, skills, and attitudes. This qualitative study aimed to investigate the teachers' perceptions since they will define the profile of the graduates and the curricular design of one of the major Civil Engineering courses in the region, based on data from Brazilian government agencies. A semi-open questionnaire was applied, and the results revealed a limited understanding of the concept of competence, in which the term was often viewed as a synonym forskill. In addition, $80 \%$ of the teachers did not perceive the absence of attitudes in their definition of competence. Keywords: competence, learning, perception, attitude
\end{abstract}

\section{Introdução}

Com o advento das Diretrizes Curriculares Nacionais do curso de Graduação em Engenharia (DCNs de Engenharia), as quais entraram em vigor em 2019, uma questão premente se descortinou: o Ensino de Engenharia deveria ser orientado por competência. Contudo, o que viria a ser competência?

Fazendo o recorte para as instituições de ensino superior públicas no Estado do Pará, pelo fato de estas apresentarem melhores índices, na região amazônica, nas avaliações do Instituto Nacional de Estudos e Pesquisas Educacionais Anísio Teixeira (Inep), podendo assim, serem consideradas referências, pode-se notar

${ }^{1}$ Universidade Federal do Sul e Sudeste do Pará. Brasil. Email: profnasicmento@unifesspa.edu.br 
que na totalidade dos seis cursos públicos de Engenharia Civil ofertados no estado, todos, consideram a tratativa do tema como uma listagem, em forma de quadro, o qual é denominado "habilidades e competências".

Com exceção do curso ofertado pela Universidade Federal do Pará, na cidade de Belém, que data sua fundação dos primórdios da Engenharia Civil no Pará, do ano de 1931, nas demais instituições, os cursos são todos fundados na primeira e segunda década do século XXI, entretanto, permanece a consideração de competências e habilidades enquanto uma listagem, o que é considerado inadequado, com base na revisão bibliográfica realizada por Scallon (2015).

Nessa conjuntura, é interessante se refletir que ideias e percepções os docentes possuem em relação ao termo Competência, o qual será tratado neste trabalho como um construto, que pode ser observado por meio de conhecimentos, habilidade e atitudes, na proposta de constituição realizada por Durad (2000).

Essa abordagem se faz válida, uma vez que, a construção de Projetos Pedagógicos apresenta intrínseca relação com os seus autores, sendo os docentes, os principais autores desse documento, logo, a percepção que os mesmos possuem do constructo Competência influência como o mesmo será tratado na realidade de formação dos egressos.

Essa preocupação se faz presente, pois, além da proximidade do prazo final para início da implantação das mudanças (2021), percebe-se que elas são crucias para que os egressos estejam minimamente inseridos nas modificações do mundo do trabalho para a próxima década, ao menos nas perspectivas apontadas por Marcial (2019), no relatório Megatendências 2030, publicado pelo Instituo de Pesquisas Econômica Aplicada.

Por isso, esse trabalho avaliou por meio de um questionário eletrônico o que os docentes de um dos cursos ofertados por instituição de ensino superior pública do estado do Pará, que oferta o curso de Engenharia Civil, consideram por competência e qual conceito eles pretendem adotar para construção do Projeto Pedagógico do curso.

\subsection{Referencial Teórico}

Duran (2000) apresenta o conceito de competências enquanto um construto tripartite constituído por conhecimento, habilidades e atitudes, nesse sentido, para o autor, a competência seria a propriedade do indivíduo de conhecimentos (saberes técnicos, informações), que podem ser utilizadas de maneira prática, configurando nesses temos as habilidades, sendo que o indivíduo teria uma preferência por obter tais conhecimentos e a vontade de aplica-los, assim, possuindo atitude.

Desta forma, percebe-se uma íntima relação entre a competência (conhecimentos, habilidades e atitudes) e a demanda por um contexto, na proposição realizada por Le Boterf (1994), na qual se faz necessário que a competência seja colocada em ação para que a mesma possa ser identificada. Para Le Boterf (1994), competência seria uma capacidade do indivíduo de reunir recursos (conhecimentos), saber utilizá-los (habilidade) para resolver um problema. Pode-se inferir esse resolver um problema, como uma ação que depende da vontade individual, nesse sentido, uma atitude, de querer mobilizar conhecimentos e habilidades para alcançar uma dada realização.

Observa-se nesse ponto de reflexão que existe minimamente, apoiando-se nas considerações de Scallon (2015), três momentos distintos, se for considerar a relação de ensino-aprendizagem: 1. A concepção da oportunidade de demonstração da competência; 2 . Julgamento do desempenho da demonstração da competência; e 3 . Inferir o desenvolvimento da competência.

Percebe-se nesse ponto que, a simples tabulação de scores pode não ser a métrica mais adequada para avaliar o desenvolvimento de competência, sendo que a mesma, precisará ser indiretamente observada, pois, enquanto 
construto, é com a manifestação dos conhecimentos, aplicandos em um contexto, no qual o indivíduo demonstre conseguir aplica-los (habilidades) e tenha interesse, disposição e inclinação a querer realizar esse circuito, ou seja, tenha atitude. Caso se pense que pode existir uma gradação no desempenho do indivíduo, percebe-se a proximidade com uma questão mais qualitativa do que quantitativa, fazendo que, caso se almeje a utilização de scores, se faça necessária a construção do significado qualitativo do mesmo.

Caso se adote esse pressuposto, de demanda de um contexto, para que a competência possa se manifestar enquanto desempenho, se faz necessário verificar se essa ideia é compartilhada pelos docentes ou eles apresentam outras concepções divergentes a literatura de referência sobre o tema.

\section{Metodologia}

Trata de uma pesquisa descritiva, realizada por meio de um estudo de caso, se propondo a verificar uma realidade especifica, descrevendo como ela se configura, no intuito de subsidiar informações que possam ser generalizadas (GERHARDT; SILVEIRA, 2009).

Se fez uso de um questionário semiaberto, composto de quatro questionamentos: 1 . De maneira sucinta, o que você considera competência. 2. Dada uma Escala Likert, o quanto você julga que competências podem se manifestar por meio do desempenho na realização de uma ação em um contexto específico. 3 . Leia o trecho e informe se o mesmo é uma competência: "Utilize os conhecimentos de desenho técnico, especificamente os ligados a representação gráfica, para produzir uma maquete que represente uma edificação de valor histórico". 4. Leia o trecho é informe se o mesmo é uma competência: "Calcular área necessária para instalação do canteiro de obras, atendendo os requisitos da NR-18".

O primeiro questionamento se propõe a levantar dados que permitam avaliar as concepções que moldam a ideia de competência dos docentes, se fez essa avaliação por meio da análise de conteúdo (BARDIN, 2011), observando que termos são adotados e que frequência esses termos aparecem. O segundo questionamento avaliou o quão próximo a ideia de competência é entendida enquanto um construto que pode ser percebido por meio da manifestação do desempenho, na percepção dos docentes. A Escala Likert variou de 1 a 5 , sendo nessa escala 1 Discorda totalmente, 2 Discorda, 3 Indeciso, 4 Concorda e 5 Concorda totalmente.

O terceiro questionamento se propõe a aferir se os docentes fazem distinção entre competência e habilidade, enquanto que o quarto questionamento se propõe verificar se esses docentes vislumbrar uma distinção sobre competência e a manifestação da mesma (desempenho).

A pesquisa não se propõe em ser exaustiva, mas, em elucidar as ideais fundamentais sobre a percepção de competência, para que se possa apoiar o processo decisório da construção de um paradigma de formação de egressos pautados em competências, divergente ao tradicional ensino alicerçado em memorização e execução de tarefas, regulamente empregado. Assim, foram avaliadas as respostas de cinco docentes, os quais irão realizar a construção do desenho curricular do curso, pautado em ensino-aprendizagem baseada em competências.

\section{Resultados}

Observando as respostas dos docentes para o questionamento "De maneira sucinta, qual conceito você atribui a "competência"?", é possível inferir uma visão bastante atrelada entre competencia e habilidade enquanto sinônimos, não se percebendo uma distinção, entre os dois termos, ambos ligados a uma realização, o que não é extamente o que expressa o conceito de competencia proposto por Durad (2000) e Sacallon (2015). As respostas dos docentes foram agrupadas, excluído-se artigos, preposições e conjunções, formando a Figura 01. 
Figura 1

Nuvem de palavras com as respostas sobre o conceito de competência

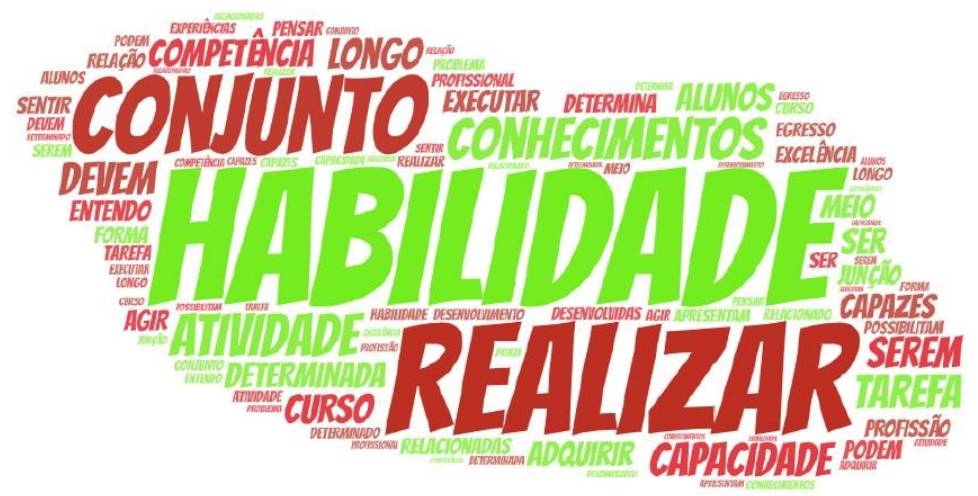

Fonte: Autor, 2021

Em suas respostas percebe-se a conceituação de competencia com o uso do conceito de habilidade, proposto por Scallon (2015), como também, não viuzalizando a habilidade como um componente da competencia, como exposto por Durand (2000), ou seja, a competência seria a habilidade de fazer algo, a forma de fazer algo, saber fazer algo.

Em relação ao segundo questionamento "o quanto você julga que competências podem se manifestar por meio do desempenho na realização de uma ação em um contexto específico", os resultados, realizados a partir da Escala Likert, nota-se que se $40 \%$ concorda com a afirmação, em contrapartida, $40 \%$ sente-se indeciso sobre.

Figura 2

Opnião em relação a afirmação do segundo questionamento.

(1. Discorda Totalmente; 2. Discorda; 3. Indeciso;

4. Concorda; 5. Concorda Totalmente).

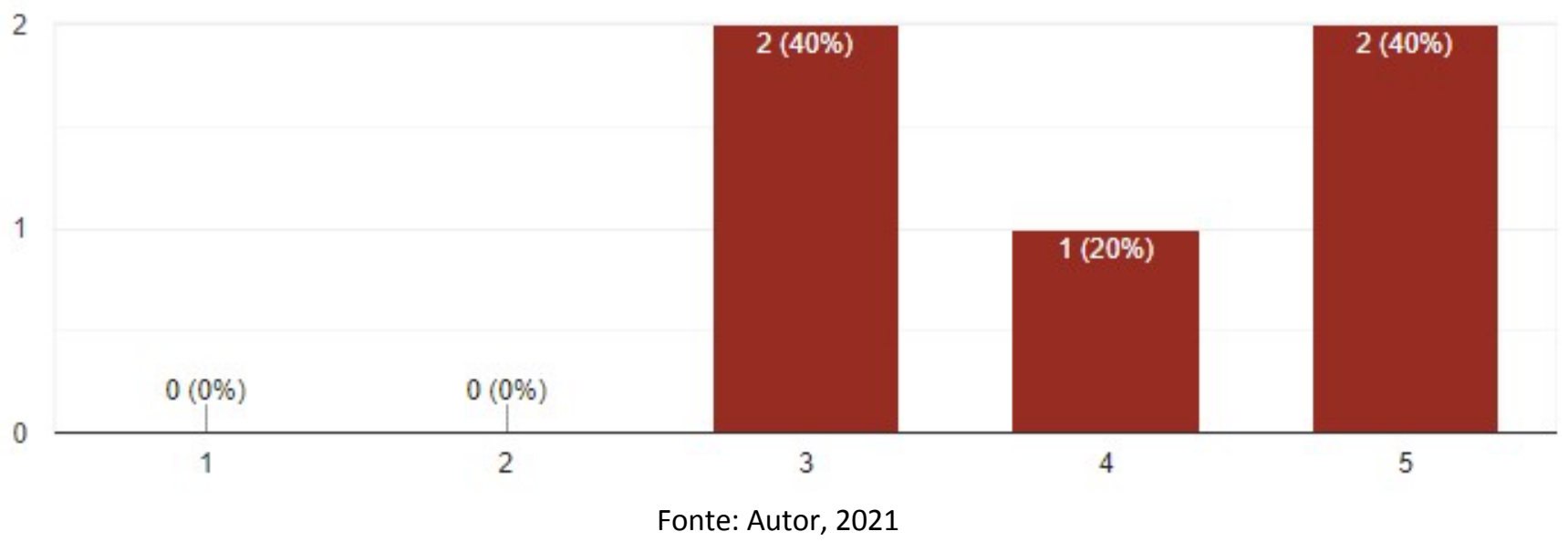

É válido frisar que, por mais que está pesquisa seja qualitativa, assim, não se atenha ao número de docentes, são os docentes que definiram o perfil do curso, desenho curricular, escolherão as estratégias de aprendizagem, focadas ou não em uma aprendizagem em competências, assim, é necessário que políticas de apoio sejam realziadas, para que esses docentes tenham suporte nessa mudança de paradigma educacional.

Considerando as respostas para o terceito questionamento, percebe-se que $80 \%$ dos docentes não vizualizam a necessidade da componente atitude, como uma integrante de uma competências, uma vez que, a afirmação 
realizada no terceiro questionamento não possui nenhuma atitude descrita, apenas o uso de conhecimento para realização de uma habilidade.

No último questionamento, 60\% não identificou o trecho "Calcular área necessária para instalação do canteiro de obras, atendendo os requisitos da NR-18" como sendo uma competencia, o que de fato ele não é, figura apenas como uma habilidade. O que é animador, por ser a maioria, entretanto, ainda sim, considerando que $80 \%$ não percebe a demanda da componente atitude ausente em uma definição incompleta de competencia, coaduna com a interpretação da conceituação realizada pelos docentes, no primeiro questionamento, representando a demanda por ações de capacitação pedagógica.

Assim, pode-se perceber a importancia que, no planejamento estratégico dessa mudança pedagógica (adoção da aprendizagem por competência), sejam fornecidos treinamentos e capacitações, os quais podem aumentar as oportunidades para que os docentes possam: desenvolver as competências didáticas e pedagógicas necessárias para tal modificação de postura de ensino-aprendizagem.

\section{Conclusões}

Os resultados, que não se propunham como exaustivos, conseguem qualitativamente expor a demanda por capacitação pedagógica, para que os docentes possam incorporar no desenho curricular o paradigma do ensinoaprendizagem baseado em competências, compreendendo competência, como a demonstração de desempenho, formada por conhecimentos, habilidades e atitudes, como exposto nas definições de Durand (2000) e Scallon (2015).

Por mais que a pesquisa exponha resultados de um amostra pequena, é válido frisar que essa amostra é a que será responsável por definir o perfil de egressos de gerações de Engenheiros Civis, em um dos cursos de referencia na Amazônia Oriental. Dessa forma, os resultados podem ser subsidiários para necessárias tomadas de decisões sobre a implantação da mudança de paradigma de ensino-aprendizagem, agora, focado em competências.

\section{Referências bibliográficas}

BARDIN, L. Análise de conteúdo. São Paulo: Edições 70, 2011. 229 p.

DURAND, T. L'Alchimie de la compétence. Revue Française de Gestión, n. 127, p. 84-102, janv./febr. 2000. Disponível em: https://www.cairn.info/revue-francaise-de-gestion-2006-1-page-261.htm\#. Acesso em: 01 de setembro de 2020. DOI: 10.3166 / rfg.160.261-292.

GERHARDT, T. E.; SILVEIRA, D. T. Métodos de pesquisa. Organizado por: Tatiana Engel Gerhardt e Denise Tolfo Silveira; coordenado pela Universidade Aberta do Brasil - UAB/UFRGS e pelo Curso de Graduação Tecnológica - Planejamento e Gestão para o Desenvolvimento Rural da SEAD/UFRGS. - Porto Alegre: Editora da UFRGS, 2009. Disponível em: https://lume.ufrgs.br/handle/10183/52806. Acesso em 18 de agosto de 2020.

LE BOTERF, G. De la compétence - essai sur un attracteur étrange. Paris: Les éditions d'organisations, 1994. $176 \mathrm{p}$.

MARCIAL, E. C. Megatendências mundiais 2030 : o que entidades e personalidades internacionais pensam sobre o futuro do mundo? : contribuição para um debate de longo prazo para o Brasil. Organizadora: Elaine C. 
Marcial. Brasília: Ipea 2015. 175 p. Disponível em: https://ppgtic.ufsc.br/files/2015/11/151013 megatendencias_mundiais_2030.pdf. Acesso em 01 de setembro de 2020.

SCALLON, G. Avaliação da Aprendizagem numa Abordagem por Competências. Curitiba: PUCPress, 2015.

Esta obra está bajo una Licencia Creative Commons

Attribución-NoCommercial 4.0 International

\section{(cc) BY-NC}

